\title{
Effect of 6 Weeks of Preseason Concurrent Muscular Strength and Plyometric Training in Professional Soccer Players
}

\author{
${ }^{1}$ Amrinder Singh, ${ }^{2}$ Kartik Kulkarni, ${ }^{3}$ Shweta Shenoy, ${ }^{4}$ Jaspal Sandhu
}

\begin{abstract}
The purpose of this study was to compare the effects of combined strength and plyometric training with soccer training alone on strength and power-related measurements in professional soccer players. Subjects were randomly divided into two groups: group EG $(n=14)$ performed heavy resistance and plyometric training thrice a week during 6 weeks training period in addition to 6-8 soccer sessions per week; group CG $(n=14)$ performed $6-8$ soccer sessions a week. EG significantly increased $(p<0.05)$ ball shooting speed and agility but showed no changes in body mass. Within-subject improvement was significantly higher $(p<0.01)$ in the EG compared with the CG for vertical jump height, 10 and $30 \mathrm{~m}$ sprint times, distances covered in the Yo-Yo intermittent recovery test. Plyometric can be concurrently performed with high load muscular strength training to enhance soccer players' explosive performances.
\end{abstract}

Keywords: Soccer, Combined training, Weight training, Periodization, Intermittent, Plyometrics.

How to cite this article: Singh A, Kulkarni K, Shenoy S, Sandhu J. Effect of 6 Weeks of Preseason Concurrent Muscular Strength and Plyometric Training in Professional Soccer Players. J Postgrad Med Edu Res 2014;48(1):27-32.

Source of support: Nil

Conflict of interest: None

\section{INTRODUCTION}

During a 90-minute football match, professional football players make numerous explosive bursts, like kicking, tackling, jumping, turning, sprinting and changing pace. ${ }^{1}$ Speed strength, also known as power, is very crucial for the performance in sports, where changes of direction, acceleration and jumps are of importance. ${ }^{2}$ Hence, strength and power in the leg muscles are important for the professional football players.

Various explosive activities are required in soccer, such as jumping, kicking, tackling, turning, sprinting,

\footnotetext{
${ }^{1}$ Assistant Professor, ${ }^{2}$ Research Scholar

${ }^{3}$ Associate Professor, ${ }^{4}$ Professor and Dean

1,3,4 Department of Sports Medicine and Physiotherapy Guru Nanak Dev University, Amritsar, Punjab, India
}

${ }^{2}$ Department of Sports Medicine, Guru Nanak Dev University Amritsar, Punjab, India

Corresponding Author: Amrinder Singh, Assistant Professor Department of Sports Medicine and Physiotherapy, Guru Nanak Dev University, Amritsar, Punjab, India, Phone: 9501114474, e-mail: singhamrinder_30@yahoo.com and changing pace. ${ }^{3}$ Improvements of these explosive performances have been reported after strength training that increased the available force of muscular contraction in appropriate muscle groups. ${ }^{4,5}$ In addition, it has been reported that jump height $(\mathrm{r}=0.78), 10 \mathrm{~m}(\mathrm{r}=0.94)$, and $30 \mathrm{~m}(\mathrm{r}=0.71)$ sprint performances are highly correlated with maximal muscular strength in professional soccer players. ${ }^{6}$ Muscular strength could be increased by two mechanisms: muscular hypertrophy and neural adaptation. ${ }^{4}$ The former increases the cross-sectional area of muscle and results in greater body mass, which is generally not desirable in soccer players because the extra weight may decrease overall performance. ${ }^{3}$ Alternatively, neural adaptation enhances muscle strength by recruiting more muscle fibers while causing minimal increase in body mass. ${ }^{4}$ Therefore, to maximize strength gains without an increase in body mass, the training program for soccer players who already have sufficient muscle mass should consist of high load and short repetition sets (i.e. 4-6 RM) for 3 to 4 sets $^{4}$ with 2 to 5 minutes of rest in between sets. ${ }^{7}$

Plyometric training - jumping, bounding and hopping exercises that use the stretch shortening cycle of the muscle unit-have consistently been shown to improve the production of muscle force and power. ${ }^{8,9}$ In particular, the fast force production of the trained muscle improves, coupled with smaller increases in maximum isometric force ${ }^{8}$ These physiological adaptations have facilitated increases in vertical jump height ${ }^{9-12}$ and decreases in sprint and acceleration times. ${ }^{9}, 13-15$

Plyometric training involves exercises where the active muscles are stretched prior to its shortening. Plyometric exercises can be done either with or without external load, and both modalities have been shown to increase power, jumping height and sprint performance. ${ }^{12,15,16}$ However, contradictory results exist regarding the effects of plyometric training on speed-power parameters ${ }^{12,17}$ as well as for the effect of heavy strength training. ${ }^{12,18,19}$ Heavy strength training and plyometric training may affect different aspects of power-related skills. Consequently, it has been suggested that combining heavy resistance training and plyometric training improves power and power-related skills to greater extent than any of the two training modalities alone. ${ }^{20}$ In the majority of studies in this field, data supports the 
hypothesis that combining heavy strength training and plyometric exercises is superior to only training one of the training modalities. ${ }^{18-22}$

An 8-week combined strength, ballistic and on-court (including plyometric actions) training program in elite volleyball players resulted in superior jump performance compared to strength or on-court training only. ${ }^{23}$ We are not aware of any controlled studies in professional soccer players which focus on effects of heavy strength training with or without plyometric exercises on important skills in soccer like maximum power, jump and sprint performances. Therefore, the purpose of this study was to compare the effects of combined strength and plyometric training with soccer training alone on power-related skills in professional soccer players. The intervention (6-week) took place in the preseason preparation phase, including 6 to 8 soccer sessions a week.

\section{MATERIALS AND METHODS}

\section{Experimental Approach to the Problem}

To examine the effects of preseason concurrent strength and plyometric training on professional soccer players' physical performance, all players participated in the pretest to measure their baseline performances. Specifically, all players participated in two test sessions separated by 4 days in the following sequence:

Day 1-anthropometry measurements, isokinetic strength testing, maximal vertical jump, ball-shooting, 30-m sprint, and agility and day 2 -Yo-Yo intermittent recovery test (YYIRT). Players had a 10-minute warm-up consisting of slow jogging and static and dynamic stretching prior to the test. There were 5-minute rests between tests for full recovery. In addition, the maximal muscular strength test was conducted 5 hours after the YYIRT. After the pretest, both the experimental group $(\mathrm{EG}, \mathrm{n}=14)$ and control group $(\mathrm{CG}, \mathrm{n}=14)$ received 6 weeks of preseason soccer training, with the EG receiving additional concurrent muscular strength and plyometric training. The muscular strength training was performed on Monday and Thursday mornings, each lasting for 60 to 90 minutes, whereas the plyometric training lasting for 10 minutes was performed on Wednesdays at the end of the 90-minute soccer training session. After 6 weeks of training, all players participated in the post-test, and these values were compared with those of the pretest to examine the concurrent training effects. All tests were performed at approximately the same time of the day with similar environmental conditions.

Performance tests that are specific to soccer match performance were used in the present study. In this regard, it has been shown that maximal vertical jump is the most discriminating explosive performance variable for soccer players. ${ }^{24}$ A $30 \mathrm{~m}$ sprint with $10 \mathrm{~m}$ lap time has been suggested as the standard sprint test for soccer players. ${ }^{3}$ The YYIRT is a soccer-specific test addressing both aerobic and anaerobic metabolism of players. ${ }^{25}$

\section{Subjects}

Twenty-eight professional male soccer players competing at the national level in India participated in the study.

Before the start of the league season, there were 8 weeks of preseason training after all players had returned from their $\sim 45$ days off-season break in which no soccer training or fitness training were performed. During the preseason phase, the players had 6 to 8 soccer training sessions per week, each lasting for $\sim 90$ minutes. Each training session generally consisted of a 10-minute warm-up, 30 minutes of technical training, 30 minutes of tactical training, 15 minutes of simulated competition and a 5-minute cooldown. In contrast, players had 5 to 6 soccer training session per week, each lasting for; 90 minutes during the season. During the season, players had no more than one muscular strength training session per week to maintain their body strength. The first team served as the EG $(n=14)$, reserve team was the CG $(n=14)$; goalkeepers were excluded from this study. Their body mass, height and body mass index are shown in Table 1. The study protocol was fully approved by the Ethics Committee, Faculty of Sports Medicine and Physiotherapy, Guru Nanak Dev University, Amritsar. During the study course, all players were instructed to maintain normal daily food and water intake, and no dietary interventions were undertaken.

\section{Anthropometric Measures}

Height and body mass were collected using a stadiometer, and electronic scale (Atco, India). Skinfold thickness was measured three times at each site using Harpenden calipers (Lange, Cambridge, MA, USA) and the median of these results was used to estimate the percentage of body fat using the sum of four sites (biceps, triceps, subscapular and suprailiac) according to previously established methods. ${ }^{26}$

\section{Isokinetic Strength Testing}

Lower limb strength was assessed for the knee extensors and knee flexors of each players dominant kicking leg. Maximal isokinetic concentric strength at $60^{\circ} . \mathrm{s}^{-1}$ was measured using an isokinetic dynamometer (Kinitech Multijoint Testing Unit, V5.16, Medisport Engineering, Australia). Five maximal repetitions encompassing the full range of concentric extension and flexion were collected for each muscle group, with two minutes rest between repetition. ${ }^{27}$

\section{Maximal Vertical Jump}

Players in barefoot condition started from an upright standing position. Players were required to perform a 
Effect of 6 Weeks of Preseason Concurrent Muscular Strength and Plyometric Training in Professional Soccer Players

\begin{tabular}{|c|c|c|c|c|}
\hline & \multicolumn{2}{|c|}{ Experimental group $(n=14)$} & \multicolumn{2}{|c|}{ Control group $(n=14)$} \\
\hline & Pre & Post & Pre & Post \\
\hline Body mass $(\mathrm{kg})$ & $72 \pm 2.54$ & $72.14 \pm 1.91$ & $71.51 \pm 2.47$ & $72.39 \pm 2.39$ \\
\hline Height (m) & $1.73 \pm 0.037$ & $1.73 \pm 0.037$ & $1.72 \pm 0.024$ & $1.72 \pm 0.024$ \\
\hline Body mass index $\left(\mathrm{kg} \cdot \mathrm{m}^{-2}\right)$ & $24.53 \pm 1.08$ & $24.122 \pm 1.10$ & $24.10 \pm 0.89$ & $24.39 \pm 0.85$ \\
\hline
\end{tabular}

Values are mean \pm SEM

countermovement jump vertically with arm swing. Jump height was determined by the portable platform (Kinematic Measurement System, Australia), based on the flight time. ${ }^{28}$

\section{Yo-Yo Intermittent Recovery Test}

The YYIRT protocol mimics the soccer-specific exercise pattern. ${ }^{25}$ The YYIRT consists of $2 \times 20 \mathrm{~m}$ bouts of shuttlerunning performed at increasing speed, interspersed by 10 seconds of active recovery (slow jog or walk), that are directed by the prerecorded acoustic signals. In this test, the running speed is progressively increased from 10 to $19 \mathrm{~km} . \mathrm{hr}^{-1}$ with a maximum total distance that can be covered during the test of $3,640 \mathrm{~m}^{25}$

\section{Agility and Sprinting Performance}

Agility and sprinting tests were measured using stopwatch. Reliability of the timing method was performed using the $10 \mathrm{~m}$ sprint since it is the test with the shortest duration and therefore any error in measurement would be magnified. Sprint testing was conducted on a football ground with the athletes completing three $10 \mathrm{~m}$ sprints before progressing to the $30 \mathrm{~m}$ sprints. Approximately, two-minute rest was allowed between each sprint and, during this time, the participants walked back to the starting line and waited for the next sprint.

The agility was assessed using the illinois agility test on an outdoor grass pitch. ${ }^{29}$ This test requires players to perform 12 changes of directions while avoiding obstacles at set position. ${ }^{30,31}$

\section{Maximal Ball Kick Velocity}

A ball of FIFA standard size and inflation was kicked $4 \mathrm{~m}$ toward a $1 \times 1 \mathrm{~m}$ target. ${ }^{28}$ Players were asked to shoot the ball as hard as possible and five shots were allowed for each player with 1 minute rests in-between. ${ }^{28}$ Ball speed was measured by a Radar Gun (Bushnell Velocity, USA) located $0.3 \mathrm{~m}$ from the stationary ball and pointed toward the target as directed.

\section{Muscular Strength Training}

The following exercises were performed twice a week for 6 weeks in a straight set (i.e. 1 exercise after another) for four sets each with $6 \mathrm{RM}$ and 3-minute rest between sets to maximize strength gains by neural adaptation: high-pull, jump squat, bench press, back half squat and chin-up. The loads were increased each time the player successfully completed the work load of the previous training with $5 \mathrm{~kg}$ increments for jump squat and back half squat and $2 \mathrm{~kg}$ increments for high-pull, bench press and chin up.,7 This type of strength training has been reported to induce minor muscular hypertrophy ${ }^{34}$ and did not interfere with the development of aerobic endurance. ${ }^{33}$

\section{Plyometric Training}

Plyometric training was undertaken once a week for 6 weeks. Participants in the experimental group performed exercises that always began with a countermovement, defined as a flexion of the knees. During rebound exercises, participants in this group were told to 'damp' their landings each time and to gain maximum height through knee flexion. The other plyometric drill was depth jump exercise which always began with a drop from a height $(40 \mathrm{~cm})$. Participants while performing the depth jump were instructed to minimize ground-contact time while maximizing height. These instructions were emphasized during every session through the use of demonstrations, verbal cues and exercise sheets.

The intensity of each program was subjectively equated using Chu's, ${ }^{35}$ Potach and Chu's ${ }^{36}$ classification of plyometric exercise intensities. The type of exercise that each group performed was matched by intensity and, where possible, by similar jumps. The height of the depth jump box remained at $40 \mathrm{~cm}$ to ensure that intensity increased as a function of exercise and not as a function of increased eccentric load, which could not be manipulated in the counter movement jump condition.

Sessions began at 80 foot contacts and progressed to 120 by the end of training. ${ }^{36}$ The program was incorporated into their usual twice-weekly training regime. Participants also continued their usual competitive program of matches.

\section{STATISTICAL ANALYSIS}

All values given in the text, Figures and Tables are represented as mean $\pm \mathrm{SE}$. A one-way analysis of variance (ANOVA) was used to determine significant differences between the EG and CG groups. After we had pooled the two intervention groups, Scheffe's test were used to compare relative changes from before to after training between the EG and CG groups. Scheffe's tests were used to test for significant changes within groups from before to after 
training. The level of significance was set at $p \leq 0.05$. Data analysis was performed using SPSS (version 20.0, SPSS Inc, Chicago, Ill).

\section{RESULTS}

After 6 weeks of concurrent training, strength of the lower limb flexor muscles increased from $137.07 \pm 3.51 \mathrm{~nm}$ to $148.07 \pm 4.66 \mathrm{~nm}(+8.02 \pm 2.13 \mathrm{~nm}, \mathrm{p} \leq 0.05)$ and lower limb extensor muscles strength increased from $212.85 \pm$ $4.62 \mathrm{~nm}$ to $225.71 \pm 5.16 \mathrm{~nm}(+6.04 \pm 1.21 \mathrm{~nm}, \mathrm{p} \leq 0.05)$ in the EG. In addition, no differences were observed in height, body mass or body mass index (BMI) in both groups compared to the pretest $(\mathrm{p}>0.05)$ (Table 2).

The EG showed significant within-subject improvement in vertical jump height $(+7.91 \pm 12.95), 10 \mathrm{~m}(-4.24$ secs, $\mathrm{p} \leq 0.05)$ and $30 \mathrm{~m}(-2.88$ secs, $\mathrm{p} \leq 0.05)$ sprint times, YYIRT (186 m), following the concurrent training, whereas CG showed significant improvement only in YYIRT $(+212 \mathrm{~m})$ over the same training period (Graph 1). There was significant improvement in agility and ball shooting speed in the EG group. After 6 weeks of training, the EG had a higher percentage improvement in vertical jump height, $10 \mathrm{~m}$ and $30 \mathrm{~m}$ sprint times, YYIRT, shooting performance compared with that of the CG. Statistical power analysis indicated strong effects $(0.05)$ of concurrent training on vertical jump height, 10 and $30 \mathrm{~m}$ sprint times but only a moderate effect on YYIRT and a small effect on HR max (Graph 2).

\section{DISCUSSION}

The results of the present study supported our hypotheses that concurrent training would improve both explosive performances and aerobic endurance of professional soccer players. This study showed that professional soccer players concurrently trained with muscular strength and plyometric training $(\mathrm{EG})$ had significantly $(\mathrm{p}<0.05)$ higher percentage improvement in vertical jump height, 10 and $30 \mathrm{~m}$ sprint times, agility and ball shooting speed compared with soccer training alone $(\mathrm{CG})$. Moreover, after 6 weeks of concurrent training, the body mass of the EG was similar to the pretest ( $\mathrm{p}$-value 0.05 ), which could be explained by the strength training protocol selected in the present study (4 sets of $6 \mathrm{RM}$ ) that prevents muscle hypertrophy. Therefore, the potential negative effect of muscular strength training on aerobic endurance (reduced mitochondrial density and decreased oxidative enzymes activity) caused by muscle hypertrophy was minimized. Maximal muscular strength increased significantly after 6 weeks of muscular strength training in EG and corresponds to significant higher percentage improvement in vertical jump height, 10 and $30 \mathrm{~m}$ sprint times as compared with soccer training alone (CG). This agreed with previous studies which reported high correlations between muscular strength and explosive performances. ${ }^{6}$ Ball-shooting speed was changed significantly in the EG after muscular strength training in the present study. A previous study reported that ball shooting speed was positively associated with leg strength, but another study found no significant relationship between ball-shooting speed and any of the strength parameters. Furthermore, it has been reported that shooting is a multijoint activity, which is highly dependent on timing and transfer of energy between the involved body segments.

The results of this study show that strength and plyometric training can positively affect vertical jump and agility performance in soccer players, with no significant difference between modes.

Vertical jump height increased for EG group. The improvement in jump height indicates that adaptations relating to increases in leg power have occurred. The adaptations to both forms of training are likely to be neural because these predominate in the early stages of strength and power training ${ }^{37}$ and have been shown to be the main adaptation to plyometric exercise. ${ }^{8}$ Time to complete the illinois agility test decreased for EG group. In contrast to straight sprinting, ${ }^{38}$ agility involves greater emphasis on deceleration and subsequent reactive coupling with acceleration. ${ }^{38}$ Leg muscle power has been moderately

Table 2: Effects of 6 weeks of concurrent muscular strength and plyometric training on physical performances

\begin{tabular}{|c|c|c|c|c|}
\hline & \multicolumn{2}{|c|}{ Experimental group $(n=14)$} & \multicolumn{2}{|c|}{ Control group $(n=14)$} \\
\hline & Pre & Post & Pre & Post \\
\hline Vertical Jump (cm) & $56.91 \pm 5.04$ & $60.87 \pm 3.12$ & $52.38 \pm 4.84$ & $53.05 \pm 4.99$ \\
\hline Ball shooting speed $\left(\mathrm{km} \cdot \mathrm{h}^{-1}\right)$ & $101.81 \pm 1.39^{*}$ & $103.06 \pm 1.03^{*}$ & $88.15 \pm 0.74$ & $88.77 \pm 0.74$ \\
\hline 10 -sprint time $(\mathrm{s})$ & $1.88 \pm 0.012^{*}$ & $1.80 \pm 0.01^{*}$ & $1.91 \pm 0.014$ & $1.91 \pm 0.024$ \\
\hline 30-sprint time (s) & $4.522 \pm 0.029^{*}$ & $4.39 \pm 0.013^{*}$ & $4.61 \pm 0.0155$ & $4.61 \pm 0.023$ \\
\hline YYIRT (m) & $2031.42 \pm 27.97$ & $2217.14 \pm 106.07$ & $2028.57 \pm 29.05$ & $2240 \pm 35.08$ \\
\hline $\mathrm{HR}_{\max }\left(\right.$ beat.min ${ }^{-1}$ ) & $188.07 \pm 3.56$ & $187.21 \pm 3.49$ & $191.64 \pm 1.44$ & $190.71 \pm 0.99$ \\
\hline Agility (s) & $15.32 \pm 0.62^{* *}$ & $14.44 \pm 0.62^{* *}$ & $15.30 \pm 0.60$ & $15.22 \pm 0.65$ \\
\hline ISK Flex $60(\mathrm{~nm})$ & $137.07 \pm 3.51^{*}$ & $148.07 \pm 4.66^{*}$ & $137.07 \pm 3.51$ & $137.50 \pm 3.81$ \\
\hline ISK Ext 60 (nm) & $212.85 \pm 4.62^{*}$ & $225.71 \pm 5.16^{*}$ & $212.85 \pm 4.62$ & $214.0 \pm 5.06$ \\
\hline Body fat $(\%)$ & $17.36 \pm 1.00^{* *}$ & $15.75 \pm 1.19^{* *}$ & $17.28 \pm 1.30$ & $16.91 \pm 1.21$ \\
\hline
\end{tabular}

Values are mean \pm SEM; *Significant difference between pretests and post-test at $p \leq 0.01$; ** Significant difference between pretests and post-test at $\mathrm{p} \leq 0.05$; YYIRT: Yo-Yo intermittent recovery test, $\mathrm{HR}_{\max }$ : Maximal heart rate 


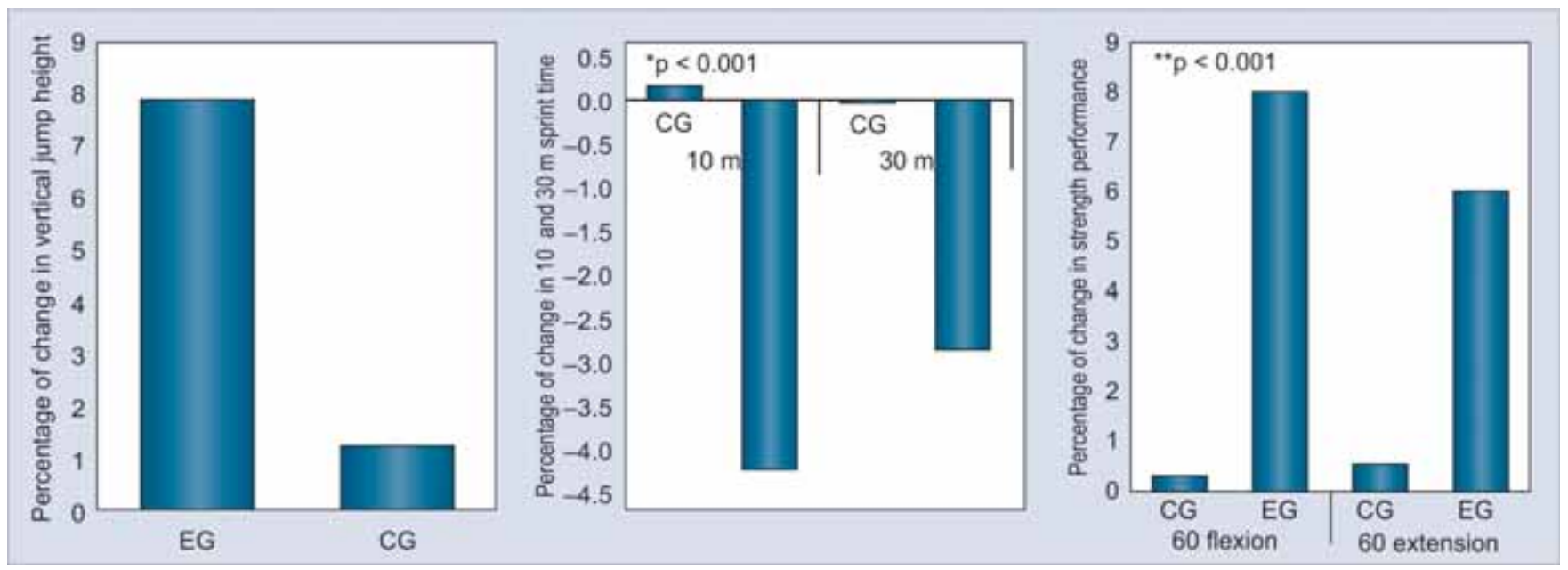

Graph 1: Percentage change of vertical jump, sprint and muscular strength performances after 6 weeks of preseason training.

Significant differences were observed in the percentage changes at $p<0.001^{*}, p<0.001^{* *}$
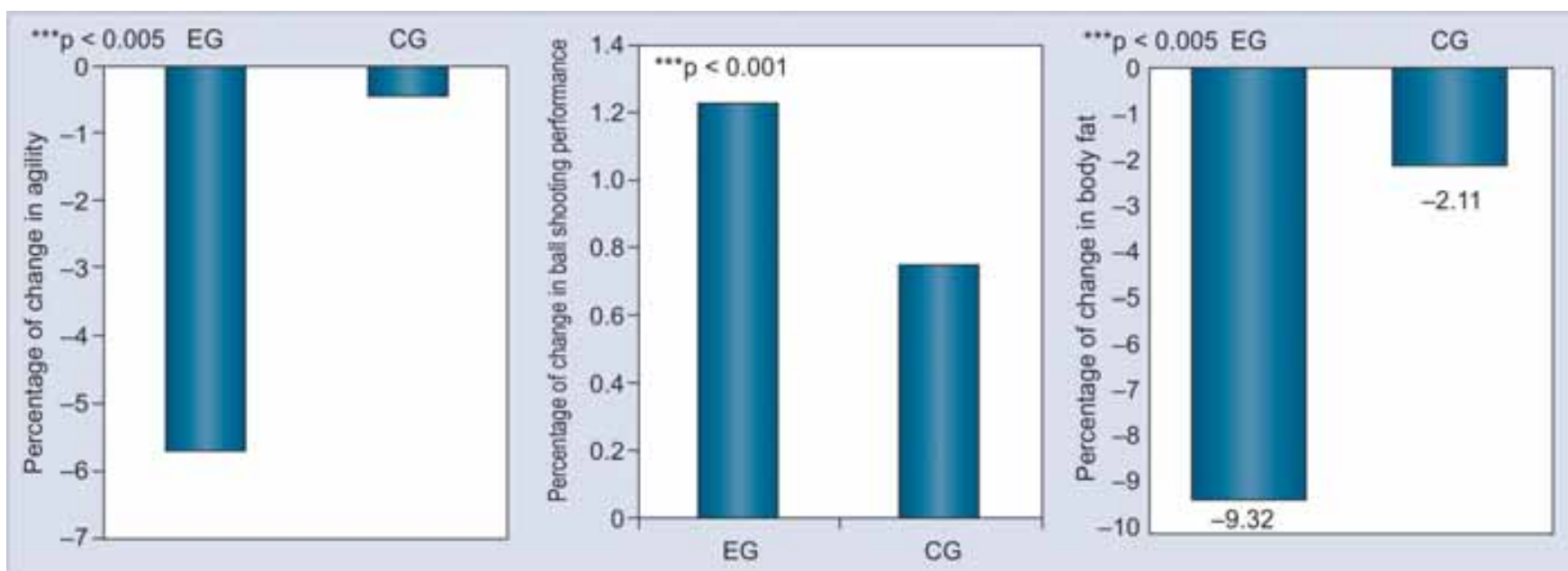

Graph 2: Percentage of change of agility, ball shooting performance and body fat percentage after 6 weeks of preseason training. Significant differences were observed in the percentage changes at $p<0.001^{* * *}, p<0.005^{* * *}$

correlated with agility ${ }^{39,40}$ as has reactive strength. ${ }^{41}$ Leg muscle power, as measured by the vertical jump, improved for both treatment groups. Neuromuscular adaptations related to firing frequencies and patterns are also likely to have occurred. ${ }^{8}$ These speculated adaptations could have improved the ability to rapidly and forcefully switch from decelerating to accelerating movements. The magnitude of increases in strength and power after training has been shown to be dependent on how similar the test is to the actual training exercise, ${ }^{37}$ reflecting the role of learning and coordination. ${ }^{42}$ Although the participants were experienced soccer players, their previous training did not include any type of jump training or specific maximal intensity change-of-direction exercises similar to those employed in the study.

\section{REFERENCES}

1. Bangsbo J, Mohr M, Krustrup P. Physical and metabolic demands of training and match-play in the elite football player. Journal of Sports Sciences 2006;24(07):665-674.
2. Newton RU, Murphy AJ, Humphries BJ, Wilson GJ, Kraemer WJ, Häkkinen K. Influence of load and stretch shortening cycle on the kinematics, kinetics and muscle activation that occurs during explosive upper-body movements. European Journal of Applied Physiology and Occupational Physiology 1997;75(4): 333-342.

3. Stølen T, Chamari K, Castagna C, Wisløff U. Physiology of soccer. Sports Medicine 2005;35(6):501-536.

4. Hoff J, Helgerud J. Endurance and strength training for soccer players. Sports Medicine 2004;34(3):165-180.

5. Manolopoulos E, Papadopoulos C, Salonikidis K, Katartzi E, Poluha S. Strength training effects on physical conditioning and instep kick kinematics in young amateur soccer players during preseason 1, 2. Perceptual and Motor Skills 2004;99(2):701-710.

6. Wisløff U, Castagna C, Helgerud J, Jones R, Hoff J. Strong correlation of maximal squat strength with sprint performance and vertical jump height in elite soccer players. British Journal of Sports Medicine 2004;38(3):285-288.

7. Baechle TR, Earle RW, Wathen D. Resistance training: Essentials of strength training and conditioning. 2nd ed. In: Baechel TR, Earle RW, editors. Champaign, IL: Human Kinetics 2000;395-426.

8. Hakkinen K, Alen M, Komi PV. Changes in isometric force and relaxation-time, electromyographic and muscle fibre characteristics of human skeletal muscle during strength training and detraining. Acta Physiol Scand 1985;125:573-585. 
9. Wagner DR, Kocak MS. A multivariate approach to assessing anaerobic power following a plyometric training program. J Strength Cond Res 1997;11:251-255.

10. Clutch D, Wilton M, Mcgown C, Bryce GR. The effect of depth jumps and weight training on leg strength and vertical jump. Res Q 1983;54:5-10.

11. Gehri DJ, Ricard MD, Kleiner DM, Kirkendall DT. A comparison of plyometric training techniques for improving vertical jump ability and energy production. The Journal of Strength and Conditioning Research 1998;12(2):85-89.

12. Wilson GJ, Newton RU, Murphy AJ, Humphries BJ. The optimal training load for the development of dynamic athletic performance. Medicine and Science in Sports and Exercise 1993;25(11):1279.

13. Delecluse C, Van Coppenolle H, Willems E, Van Leemputte, Diels MR, Goris M. Influence of high-resistance and highvelocity training on sprint performance. Medicine and Science in Sports and Exercise 1995;27:1203.

14. Kraemer WJ, Ratamess NA, Volek JS, Mazzetti SA, Gomez AL. The effect of the meridian shoe on vertical jump and sprint performances following short-term combined plyometric/sprint and resistance training. J Strength Cond Res 2000;14:228-238.

15. Rimmer E, Sleivert G. Effects of a plyometrics intervention program on sprint performance. J Strength Cond Res 2000;14: 295-301.

16. Mcbride JM, Triplett-Mcbride T, Davie A, Newton RU. The effect of heavy vs light-load jump squats on the development of strength, power, and speed. J Strength Cond Res 2002;16:75-82.

17. Lyttle AD, Wilson GJ, Ostrowski KJ. Enhancing performance: Maximal power versus combined weights and plyometrics training. J Strengt Cond Res 1996;10:173-179.

18. Harris GR, Stone MH, O'bryant HS, Proulx CM, Johnson RL. Short-term performance effects of high power, high force, or combined weight-training methods. J Strength Cond Res 2000;14: 14-20.

19. Kotzamanidis, Chatzopoulos CD, Michailidis C, Papaiakovou G, Patikas D. The effect of a combined high-intensity strength and speed training program on the running and jumping ability of soccer players. J Strength Cond Res 2005;19:369-375.

20. Adams K, O'shea JP, O'shea KL, Climstein M. The effect of six weeks of squat, plyometric and squat-plyometric training on power production. J Strength Cond Res 1992;6:36-41.

21. Fatouros I, Jamurtas A, Leontsini D, Taxildaris K, Aggelousis G, Kostopoulos N, Buckenmeyer P. Evaluation of plyometric exercise training, weight training, and their combination on vertical jumping performance and leg strength. J Strength Cond Res 2000;14:470-476.

22. Toji H, Suei K, Kaneko M. Effects of combined training loads on relations among force, velocity, and power development. Can J Appl Physiol 1997;22:328-336.

23. Newton RU, Kraemer WJ, Häkkinen K. Effects of ballistic training on preseason preparation of elite volleyball players. Med Sci Sports Exerc 1999;31:323-330.

24. Gil SM, Gil J, Ruiz F, Irazusta A, Irazusta J. Physiological and anthropometric characteristics of young soccer players according to their playing position: relevance for the selection process. J Strength Cond Res 2007;21:438-445.

25. Castagna C, Impellizzeri FM, Chamari K, Carlomagno D, Rampinini E. Aerobic fitness and Yo-Yo continuous and intermittent tests performances in soccer players: A correlation study. J Strength Cond Res 2006;20:320-325.

26. Durnin JV, Womersley J. Body fat assessed from total body density and its estimation from skinfold thickness: measurements on 481 men and women aged from 16 to 72 years. Br J Nutr 1974;32(1):77-97.

27. Sandhu JS, Thakur K, Shweta S, Ravi S. Concentric hip muscle function and quadricps: Hamstring in athlets with and without oatellofemoral pain syndrome. Ibnosina Journal of Medicine and Biomedical Sciences 2012;4(1):20-27.

28. Wong P, Chamari K, Dellal A, Wisloff U. Relationship between anthropometric and physiological characteristics in youth soccer players. J Strength Cond Res 2009;23(4):1204-1210.

29. Amiri-Khorasani M, Sahebozamani M, Tabrizi KG, Yusof AB. Acute effect of different stretching methods on illinois agility test in soccer players. The Journal of Strength and Conditioning Research 2010;24(10):2698-2704.

30. Brughelli M, Cronin J, Levin G, Chaouachi A. Understanding change of direction ability in sport. Sports Medicine 2008;38(12), 1045-1063.

31. Miller MG, Herniman JJ, Ricard MD, Cheatham CC, Michael TJ. The effects of a 6-week plyometric training program on agility. Journal of Sports Science and Medicine 2006;5:459-465.

32. Raven PB, Gettman LR, Pollock ML, Cooper KH. A physiological evaluation of professional soccer players. British Journal of Sports Medicine 1976;10(4):209-216.

33. Paavolainen L, Hakkinen K, Hamalainen I, Nummela A, Rusko H. Explosive-strength training improves $5 \mathrm{~km}$ running time by improving running economy and muscle power. J Appl Physiol 1999;86:1527-1533.

34. Kyrolainen H, Avela J, Mcbride JM, Koskinen S, Andersen JL, Sipila S, Takala TE, Komi PV. Effects of power training on muscle structure and neuromuscular performance. Scand J Med Sci Sports 2005;15:58-64.

35. Chu D. Jumping into plyometrics. Champaign: Human Kinetics, 1992.

36. Potach DH, Chu DA. Plyometric training. In: Essentials of strength training and conditioning (2nd ed). Baechle TR and Earle RW, editors. Human Kinetics 2000;427-470.

37. Sale DG. Neural adaptation to resistance training. Med Sci Sports Exerc 1988;20:S135-S145.

38. Plisk SS. Speed, agility and speed endurance development. Essentials of strength training and conditioning, (2nd ed). In: Baechle TR, Earle RW, editors. Human Kinetics, 2000; 427-470.

39. Mayhew JL, Piper FC, Schewgler TM, Ball TE. Contributions of speed, agility and body composition to anaerobic power measurements in college football players. J Appl Sport Sci Res 1989;3:101-106.

40. Negrete R, Brophy J. The relationship between isokinetic open and closed chain lower extremity strength and functional performance. J Sport Rehabil 2000;9:46-61.

41. Young WB, James R, Montgomery I. Is muscle power related to running speed with changes of direction? J Sports Med Phys Fitness 2002;42:282-288.

42. Rutherford OM, Jones DA. The role of learning and coordination in strength training. Eur J Appl Physiol Occup Physiol 1986 55:100-105. 